This is an author-produced PDF of the accepted version of an article in LANGUAGE AND INTERCULTURAL COMMUNICATION. There is a two-year embargo before a reviewed version of the article can be published on an author website.

\author{
McKinley, J., Dunworth, K., Grimshaw, T., \& Iwaniec, J. (2019). Developing \\ Intercultural Competence in a 'Comfortable' Third Space: Postgraduate Studies in the \\ UK. Language and Intercultural Communication, online 25 November 2018. \\ https://doi.org/10.1080/14708477.2018.1545028
}

\author{
Jim McKinley, University College London \\ Katie Dunworth, University of Bath \\ Trevor Grimshaw, University of Bath \\ Janina Iwaniec, University of Bath
}

\title{
Developing Intercultural Competence in a 'Comfortable' Third Space: Postgraduate Studies in the UK
}

\begin{abstract}
With the number of international postgraduate students in UK universities steadily increasing, there is great interest in understanding how institutions can more effectively meet these students' expectations and needs through programme-supported development of intercultural competence. This paper reports on a project that explored experiences and perceptions of the development of intercultural competence in a UK higher education context. Academic staff $(\mathrm{N}=8)$ and international postgraduate students $(\mathrm{N}=24)$, from a range of countries, were recruited for preliminary interviews (two staff from each of the four faculties), focus groups (students of these staff), and stimulated recall interviews (same staff). The project targeted tensions and issues occurring between the perspectives of participants. It focused on the performance and negotiation of identities in the 'third space' that emerged between participants using different cultural discourses. The findings suggest that, despite the inherent contradiction of comfort and the conflict of negotiation, efforts are made by both students and staff to create a 'comfortable' third space in which to negotiate learning. By this we mean an environment in which to negotiate learning where those present feel at ease with their own and others' cultural identities and differences. This raises significant implications for policies and practices regarding the development of intercultural competence. Specifically, the university needs to build a better understanding of how to create a 'sphere of interculturality' in which international postgraduate learning can take place.
\end{abstract}

Keywords: third space, sphere of interculturality, internationalised higher education

\section{Introduction}

As the higher education sector continues along the path of internationalisation and international student enrolment grows, academic staff and international students alike are expected to function within an often-unfamiliar environment for learning. Students' own prior learning experiences may be in conflict in such contexts. Such is often the case with postgraduate studies at UK universities where the majority of students are international, usually from other cultural and linguistic backgrounds. In such environments, students and tutors need to negotiate and develop new 'spaces' that are conducive for learning. 
The conceptual context in which people interact and forge new identities has been described by postcolonial theorists (esp. Bhabha, 1994) and by theorists of language studies as a 'third place' or 'sphere of interculturality' (esp. Kramsch, 1993). Universities in the process of internationalisation are key sites for the development of such 'spaces'. Through their core activities of teaching and research, universities are microcosms of our transnational, superdiverse, post-multicultural societies (Vertovec, 2007; 2009). They not only hold a powerful stake in intercultural interactions but also have a great responsibility in influencing the future development of those interactions within the broader society. The current qualitative study, which was designed to explore the development of intercultural competence in a UK higher education context, was informed by a combination of the concepts of 'third space' and 'sphere of interculturality'.

The study was conducted with a view to identifying the tensions and issues occurring between the attitudes and perspectives of participants and, ultimately, the implications for the policies and practices of the institution. The project involved eight academic staff and twenty-four of their international postgraduate students from across five continents and across four major discipline areas: science, engineering and design, humanities and social sciences and management. The project afforded valuable opportunities for exploring the performance and negotiation of identities within the third space / sphere of interculturality.

The key theme of this paper is the idea of a comfortable third space, which we define as an environment in which to negotiate learning where those present feel at ease with their own and others' cultural identities and differences. A comfortable third space is conducive to establishing the sphere of interculturality. Such a space is constituted by concrete guidelines that protect and respect all those involved, as well as understanding and awareness that all cultural discourses should influence and contribute to thinking and practices. There is an inherent advantage to bringing together various cultures into a single learning space, but it is not clear how to achieve the potential this advantage brings. Therefore, in this study we sought to gain an understanding of how a UK university might deal with the challenges of establishing a sphere of interculturality by developing a comfortable third space for international postgraduate studies.

\section{Conceptual Framework}

Our conceptualisation of intercultural competence is based on Deardoff's classic definition, that is as 'the ability to communicate effectively and appropriately in intercultural situations based on one's intercultural knowledge, skills and attitudes' (2006, p. 249). Our understanding of how intercultural competence can develop in the context of higher education was informed by two concepts in particular: the third space and the sphere of interculturality.

In his seminal work on postcolonial and poststructuralist theory, Bhabha $(1994$, p. 38) proposes his notion of 'the third space of enunciations' as an alternative to the dualisms that tend to dominate discussions of intercultural contact. He describes this as an 'interstitial place': one of conceptual struggle and contestation, where 'signs can be appropriated, translated, rehistoricized and read anew' (ibid, p. 55). The third space has been interpreted variously as a zone in which transgressive acts are performed, in which oppressed groups develop their courses of dissent, or in which members of both the dominant and nondominant cultures are able to experience shared perspectives and temporary affinities (Dobinson, 2014; Gutierrez, 2008; Ikas \& Wagner, 2009; LoBianco, Liddicoat, \& Crozet, 1999; Soja, 1996). 
Central also to Bhabha's vision is the notion of cultural hybridity. As Bhabha (1994) explains, within the third space, liberated from the structures and hierarchies of both their 'home' culture and the 'other' culture, social actors can (re)negotiate their identities and (re)position themselves. In our reading, we interpreted this to mean that by retaining some characteristics of the 'home' culture but also adopting some features of the new culture, they can shape hybrid identities that offer new possibilities for empowerment and change. Viewed in terms of wider social action, the third space allows for the creation of a genuinely 'international culture based not on the exoticisms of multiculturalism or the diversity of cultures, but on the inscription and articulation of culture's hybridity' (Bhabha, 1994, p. 56) [the original author's italics].

The current study was further informed by the concept of 'sphere of interculturality' as it is conceived within the field of applied linguistics (Byram, 2014; Kramsch, 1993; 2011; Kramsch \& Uryu, 2014). Kramsch (1993) introduces the concept, explaining that: 'Third place, third culture and sphere of interculturality are metaphors that attempt to capture through a place marker what is in fact a process of positioning the self both inside and outside the discourse of others' (Kramsch, 2011, p. 359). Kramsch's contribution advances our understanding by placing it in a pedagogical context. Our conceptualisation of the sphere of interculturality is that it is the result of a learning process in which individuals have gained an understanding of their own cultures and established their own notions of 'culture'.

In an era of globalised communications, mass migration, transnationalism, and transcultural flows it is increasingly common for individuals to experience a confused sense of identity (Appadurai, 2013; Pennycook, 2007; Vertovec, 2007; 2009). This is the case not only for individuals who experience an 'international' education but also for members of superdiverse societies and others who temporarily inhabit those societies. In such an environment, models that view intercultural contact in terms of individuals from one stable, relatively homogenous culture dealing with another appear increasingly outdated.

Critics have highlighted certain limitations of Bhabha's model. For instance, Kumaravadivelu (2008) warns against assuming that the margin of the third space falls equally between cultures. To do so, he argues, would be to ignore the differential power relations between 'the oppressed and the oppressor' (p. 128). Similarly, Holliday (2011, p. 164) challenges the assumption of 'an indelible line between Self and Other' since this appears to reinforce the idea that cultures are mutually exclusive. Holliday sees Bhabha's model as an instance of 'neo-essentialism': that is, an approach which seeks to present itself as more liberal in acknowledging other cultures beyond the national, but which is nevertheless largely governed by the premises of an outdated essentialist paradigm. According to Holliday (2011), the notion of a third space reifies the division between one essentialised culture and another. Instead, arguing from a position of 'critical cosmopolitanism', he prefers to view the differences between cultural domains as 'relatively blurred' and to emphasize the role of 'shared underlying universal cultural processes' ( $\mathrm{p}$. 165).

Both Kumaravadivelu (2008) and Holliday (2011) take issue with Bhabha's conceptualisation of cultural hybridity as a state which is distinct from either/or positionings. They cite poststructuralist readings, which cast individuals as simultaneously being members of multiple cultural groupings and holding multiple identities (ethnic, racial, national, gender, social class, etc.). As Holliday puts it: 'One does not have to be in-between. People have the power to be several things at once' (2011, p. 165). Indeed, it can be argued that notions of reified 'first', 'second' and even 'third cultures' seem increasingly inadequate. As a person travels through their daily life, from one moment to the next they may occupy any number of 'third spaces'. This thinking is in line with other movements within the field of applied linguistics, where lingua franca encounters are posited as new spaces for communication, 
where 'language and culture are created in each instance of communication, and are fluid and unfixed' (Galloway \& Rose, 2015, p. 229).

Nonetheless, it must be recognised that there is a disjuncture between current theory of intercultural contact and prevailing popular discourse. The constructivist, non-essentialist paradigm has gained much ground in the social sciences in recent years. But essentialist notions of culture, identity and language continue to dominate political discourse, advertising, the media, and popular literature, and therefore continue to exert a powerful influence on how people perceive and construct cultural Others. Consequently, as we shall see in the subsequent discussion, in academic contexts it is common to see participants wrestling with these contradictory constructs and definitions of culture.

With these caveats and qualifications in mind, in this article we wish to argue the concept of a comfortable third space - one that challenges interpretations of Bhabha's third space as tense and uncomfortable (cf. Zhou \& Pilcher in this issue) - provides a valuable theoretical lens through which to view the creative intercultural interactions that take place within the context of postgraduate studies. From this conceptual framework, the research questions emerged:

1. How can the university establish a 'third space / sphere of interculturality' that is conducive to the development of intercultural competence in postgraduate learning?

2. What are the challenges to the development of a 'third space / sphere of interculturality' that is comfortable for participants?

\section{Methodology}

This exploratory-interpretive study employed a multiple-case design (Yin, 2014) within a macro context, a UK university, to address the research questions. In total, there were eight cases from the institution's four different teaching faculties (engineering and design, humanities and social sciences, management, and science). Each case comprised one taught postgraduate programme. The choice of eight cases was to ensure that all of the university's teaching faculties were taken into consideration. The selection of postgraduate programmes was made on the basis that students on such courses would be likely to have a higher level of maturity and greater experience of the world outside education than undergraduate students. In addition, the selected programmes were characterised by large numbers of students paying international tuition fees, and therefore tended to be of non-British cultural origin.

There were three main methods of data collection: background interviews, classroom observation followed by stimulated recall interviews (SRIs), and focus group interviews. The first procedure was that after the primary lecturers for the programmes had agreed to participate, they began by participating in the individual background interview. The interview was designed to learn about their experience as well as teaching approach from an intercultural perspective. Second, a class taught by that participant was observed by a team member and recorded. These observations were used to provide material that could act as a stimulus for the subsequent SRIs. Given the large amount of data generated from the observations, SRI interviewers provided a focus for the interviews by initially identifying particular instances of classroom communication that appeared to be relevant to the research questions. However, the participants were also encouraged during the SRIs to comment on any aspect of the class that they wished. Third, students who attended the observed classes were invited to participate in focus group interviews, which focused on their perceptions and experiences of intercultural competence within that educational programme. The size of the focus group interviews varied according to the level of interest expressed by the students and their availability, with a mean of three participants per group. No record was maintained of 
the overall class size from which the participants were drawn, as the study was not intended to be generalisable or representative of a wider population.

The diagram below illustrates the design employed in this study. In total, there were 29 sources of data, including eight background interviews, seven classroom observations, seven SRIs, and seven focus group interviews. The discrepancy between the number of background interviews and other data sources was due to the unexpected closure of a programme after the initial interview with the staff participant was conducted. However, as the data from the interview were relevant and useful, it was decided to include them in the analysis.

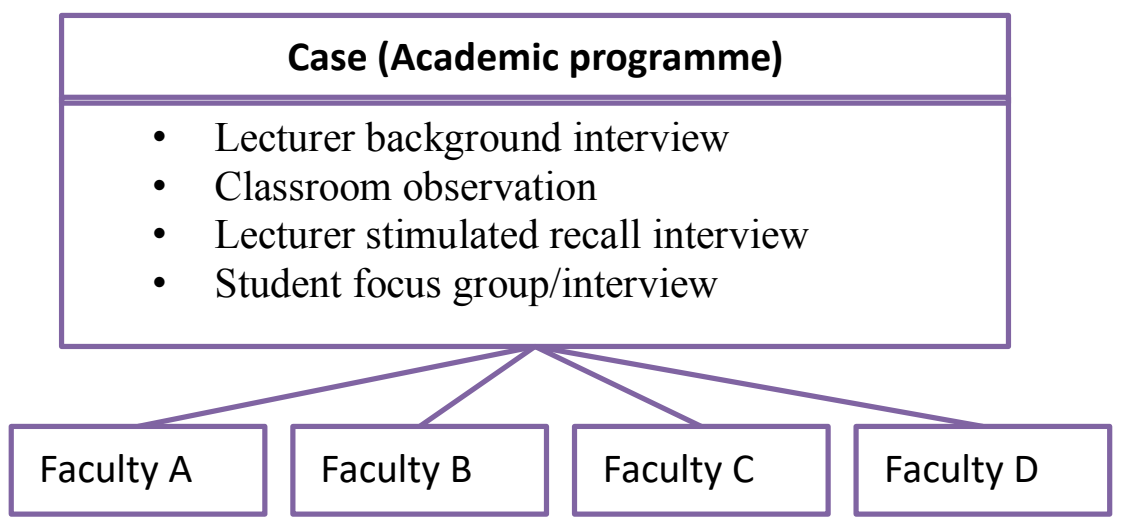

Figure 1. Methodological structure of the study

Regarding the backgrounds of the participants, of the eight academic staff participants, five were originally from outside the UK (although all were residing permanently in the UK at the time the study was conducted). All of the twenty-four student participants indicated through their contributions that they were from outside the UK (although two were originally from the UK), from a variety of countries including China, Vietnam, South Africa, India, the United States, Thailand, and Lebanon. It is important to note that given our theoretical framework, we did not specifically seek to find out where each person was from, and being 'international' was not a criterion necessary for participation. Nevertheless, it was interesting that almost all those who chose to participate could identify in some way with an international experience and may perhaps indicate that 'international' and 'intercultural' are still seen as closely associated concepts, as Piller (2012) has observed.

The researchers analysed the data thematically. To help up us firm up our categories of data, every case was examined by two members of the team. Additionally, at the commencement of the data analysis process, the first case was coded by all the team members to share our interpretations of the data and establish a consistent methodological approach. In our analysis, we identified instances in the data of recognition of, or attempts to navigate an understanding of, a comfortable third space. Examining participants' understanding of cultural differences in the sphere of interculturality, we focused on how staff and students viewed intercultural competence as multi-layered and complex, and how they shared a commitment to the value of diversity as a positive principle, a recognition of the need for high levels of intercultural competence in the workplace and agreement on the need for adjustments according to context. The codes from individual cases were then reduced into categories and organised around emerging themes. Once the within-case analysis was completed, the cross-case analysis was conducted. 
Written informed consent to participate was obtained from both staff and student participants, according to the ethical guidelines produced by the British Education Research Association (BERA). Staff were contacted by an initial email, and students were invited to participate by one of the research team who presented a handout to the class members who could then return the handout with their contact details if they were interested; there was therefore no pressure placed on students to participate from within their own programme or Department, or from the researchers. All participants were identified in data transcription and analysis solely by a numerical code, and any material considered for publication was carefully examined to exclude anything that might have identified the programme or participants.

The individual and focus group interview recordings were transcribed using a broad transcription approach, given that the analysis was to be thematic rather than discourse analytic. The language used was transcribed verbatim (i.e. not 'corrected' to native speaker norms), although pauses and hesitating devices were not included. The transcriptions were checked against the recordings for accuracy by a second reader. Each change of speaker was indicated by a new line in the transcript and all lines were numbered. The line numbers are not reproduced in this paper since they do not provide any referenceable information for the reader.

In this paper, quotations from participants are identified through the following coding system: A, B, C and D for the different faculties, divided into two for each of the two programmes (e.g. A1 B2). This is followed by the data collection technique (PI for preliminary interview, FG for focus group, SRI for stimulated recall interview). We provide quotes from a wide range of participants to ensure that we are providing holistic evidence of themes (see Goldberg and Allen, 2015). We have consciously avoided disproportionately quoting participants who may be seen as supporting our ideas, and excerpt lengths are kept to a minimum to allow for more variety of responses to be included in the article.

\section{Findings and analysis}

Within our conceptualisation of the comfortable third space, we identified several goals aimed at understanding other cultures, appreciating cultural differences, sharing one's own culture, and reflecting on one's own culture in relation to others'. After an initial analysis and generation of themes, comments from data were categorised addressing 1) interest in and awareness of culture, 2) sense of community, 3) openness to diversity, and 4) the construction of a comfortable third space, all pointing toward the establishment of the sphere of interculturality.

In this section, the four emergent themes identified above are presented in turn. These themes are not independent of each other, but rather inform each other, illuminating aspects of the 'third culture', as experienced in postgraduate programmes. The discussion of each theme will help us to address our main research questions, which concern the development of intercultural competence and the creation of a comfortable sphere of interculturality.

\section{Interest in and awareness of culture}

The questions invited participants to reflect on concepts related to the general atmosphere for international students in the classroom and the wider university, which led to issues such as culture shock, and broad references to local culture, cultural differences, and adjusting to them. While this may indicate a certain discomfort with adjustments being made in moving from one culture to another, we found that nearly all tutor participants were amenable to the adjustments made in developing intercultural competence. For example, one tutor, reflecting 
on both the students' and his own awareness of cultural differences, raised the expectation that international students will experience culture shock in the classroom. He explained that the students 'are conscious of the fact that I am conscious that they are from a different culture and this is culture shock; don't worry about it we'll sort it out' (A2 PI). The tutor emphasized that the 'sorting out' was something to be done by both the students and himself, but that it was not a deliberate act. Instead, 'sorting out' fit into our conceptualisation of a comfortable third space as it was more a universal sense of group members becoming more familiar with each other, and finding common ground through a joint effort to achieve the same goal-in this case, learning key concepts in a master's programme.

In another example, from the tutor who withdrew from the study after the initial interview, common ground was also established by conceptualising a global professional culture that supersedes cultural differences at local levels:

...so this is both the education culture the country-based culture I suppose the religious culture as well which shapes the person, but I think what we've got layered on top of that, as in all industries have, is the professional culture which is global in a way, so you know individuals operate professionally so they're obliged by the ethics and culture of that profession, so I think in a way that cuts across - it's a horizontal cut across virtually all... (C1 PI)

While awareness of cultural differences was recognised in various forms, the level of awareness was tentative. Participants avoided suggesting that their awareness was unique or lower than others' in the same context. For example, one tutor remarked, 'I'm certainly not the only one who is aware of these cultural differences, but I don't know that for a fact' (A2 PI). Such sensibility provided further evidence of awareness. However, there were also suggestions that awareness could be limiting. For example, a simple recognition of cultural difference could be considered sufficient in a classroom interaction, such as in the following, in which a staff member reflects on a student commenting on classroom participation:

'Oh, it's interesting that it means something different for somebody to say this and that for somebody else'; they might have inferred that but we didn't point it out explicitly. They all just said their beliefs and then sat down. (A1 SRI)

Such an interaction is recognized as not offering any further actions that might lead to the development of intercultural competence.

In one focus group, a student commented on the link between intercultural competence development in her studies with expectations about what she and her fellow students would face in the workplace, thus seeing intercultural competence as a transferable skill:

Because this is what we are going to face in the workplace. Exactly, it's preparing you for when you go to work, you have to meet other people you have to have people from around the world sometimes that you have to work with and they might not have the same culture or think the same way as you do so you need to at least to be able to work with them and understand their behaviour. (C2 FG)

Statements such as this acknowledge the instrumental value of intercultural competence for employability. At the same time, they are evidence that participants perceive distinctions and similarities between the 'culture of the university' and the 'culture of the 
workplace'. This implies a broader and more complex understanding of interculaturality than merely encounters between different nationalities or ethnicities.

In another focus group, students raised the important point that awareness of cultural differences was not the same as intercultural competence. Several of the students voiced concerns that intercultural competence involves more than 'just recognizing that there is a cultural difference' (A2 SRI), with one student adding that while awareness may not equate to competence, it does lead to recognition of others' (i.e. tutors') efforts toward developing intercultural competence in the classroom. This idea supports our conceptualisation of a comfortable third space, one that is achieved in a sphere of interculturality that is the result of a raised awareness of multiple cultures.

\section{Sense of community}

The reflection on interculturality in the classroom and university inevitably raised some issues related to the participants' sense of community — of connecting with others through various interactions, and being an active member of potentially diverse communities. The concept of inclusion was a key factor in identifying participants' behaviour and thinking that helped to form a sphere of interculturality. Most actions leading to a sense of community were not overt, such as the use of the inclusive pronoun 'we' by one tutor: 'I often use the word "we" in the class because I want it to be a feeling in my students that we're all participating in the process' (B2 SRI). The tutor then remarked on the inclusion value of this subtle act, on the importance of 'not referring to me and my perceptions, but I'm referring to them and me and our shared perceptions' (B2 SRI).

The context, when ideas related to a sense of community were raised, extended beyond academic locales to 'pub culture', UN-style dinners ('we all have different nationalities, you invite everybody over and you get to know each other; it's just a different culture which we love', A2 PI), and life experiences with family and friends. Most participants, students and staff alike, expressed great positivity when discussing opportunities to spend time with those from different backgrounds. For example, one (non-Asian) student commented on the value of "the different people in there they bring; I was really like really excited there was lots of Asian kids in this school...' (B1 FG). Another student commented on the positive challenges to learning that arise by bringing together different cultures: 'the most thing that you challenge is yourself not about even the culture around you, so challenging sometimes it's you know like make you learn more' (D1 FG).

There were a few mentions of barriers to a sense of community, in consideration of subtle actions, as well as the lack of overt actions. One tutor commented on the organic nature of an ability to interact in a diverse community that he had 'purely by experience or talking to friends or colleagues, there's nothing formal in it' (A2 PI). While discussing a similar notion, a student in one of the focus groups remarked that the university fails to 'capitalize on that enough; and I don't think structurally the programme is designed for us to actually interact' (A1 FG). These comments address an important point. They support arguments in recent literature that it is not good enough for a university to simply rely on the organic nature of participation in various communities, and that engagement should be actively promoted at programme design level (e.g. Jones \& Brown, 2007).

One consideration is providing interdisciplinary collaboration, which came up in preliminary interview with a tutor who spoke of a course component that had been specifically designed for students of Engineering: 
Well we have a programme called Understanding People in Organisations and we run a whole-day workshop where we ask them to expose their cultural uncertainties and feelings and it's run by Social Sciences for us, and you know it's fascinating. I sit there at the back and listen to how you know they come from a different culture and how they view things differently and they talk about how coming to the workshop you know how they felt some felt unconfident some felt bolshy, and you know that's a way of peeling back cultural differences and feelings, so we do that specifically on that one unit. (C1 PI)

The tutor understood that the workshop offered by Social Sciences offers an activity that targets cultural differences - an opportunity Engineering students may not have otherwise had in the programmes in their own faculty. The intercultural competence in this case is developed through interdisciplinary collaboration, where Engineering and Social Sciences conceptualisations come together to form the sphere of interculturality that provides a comfortable third space in which students can draw on thinking and practices from another discipline.

\section{Openness to engaging with other cultures}

The data suggest that, for intercultural competence to develop, there needs to be a certain openness to engaging with other cultures. This sub-theme, often identified as references to 'diversity', contained the greatest number of examples from the interview data, with ideas ranging from recognizing one's own limitations of, or conflicts in, understanding different cultures, to avoiding stereotypes, to a general interest in 'different kinds of thinking' (B1 PI). We recognise that 'cultural diversity' is a contentious concept, one of which Bhabha was skeptical. For the purposes of this study, we have interpreted participants' references to diversity to mean an act of engaging with other cultures.

All tutors reflected on their understanding of an openness to engaging with other cultures at some stage in the study, mostly in consideration of a need for it, for various reasons. For example, in one preliminary interview, a tutor commented, 'you need that diversity to enable us understanding, okay these are things that will work for this group, let's have some events where everyone can take part' (D1 PI). In a stimulated recall interview with another tutor, the openness to diversity was reflected in differences in religious understanding with an example from a task in architecture to plan different religious buildings:

And I think it's more on the inquisitive side, they [students] need to learn to ask questions you know, not make assumptions; in architecture it's quite common. For example we might ask Catholic students to design a mosque, and Muslim students to design a Catholic church. Not here in one of the schools where I work. You are exposed to a completely different culture, manifested in a building - it's not just the dome, it's male and female separated, and in Catholic it's all together, but in Catholics you have the hierarchy of people, the priest and the back of the church, and it helps you to start thinking about it then. The world has many colours than the black and white. (C2 SRI)

The openness to enegaging with other cultures voiced by the participants in all focus groups reflected the reality of a sphere of interculturality that either exists or does not exist in specific contexts in the university. For example, a student who, like others, expressed concern about the 'lack of diversity' (B1, FG) in the classroom due to its composition of few or no 
local students, was very positive about an activity requiring interaction via Skype. The activity, although not necessarily by design, brought much-desired diversity to the classroom, as the individual contacted was 'from a different cultural background' (B1 FG). There was also a sense of preparing for the future by maintaining an openness to diversity, as students considered the possibility that they may conduct research or work in an environment that they have not yet been exposed to. With this thinking, the student considered the pitfalls of stereotypes: 'I know how different cultures work so to go with open-minded not with that stereotype in my head already and be open and how understand how their culture is' (B1 FG). The same student later added that conflict could be avoided through openness, not being limited to 'a Western point of view'.

A general openness to enegaging with other cultures was a point of unification in several focus group interviews, with students in agreement with statements about the importance of maintaining or learning to have an open mind. This, at times, led students to be critical of the university programmes offered, challenging them as 'lacking diversity' (B2 FG). Notably, this criticality was also reflected in some tutors' interviews. One tutor remarked that the university programmes 'don't offer as many courses that talk about different regions of the world' (B2 PI). This links with our earlier finding that the participants felt the university did not provide sufficient opportunities for students to mix and interact. While students agree the university is 'international', they do not agree that it is 'diverse', contrasting with our original understanding that the selected programmes were characterised by large numbers of international students, and could therefore be assumed to be culturally diverse.

However, in general, participants focused on other dimensions of engaging with other cultures, not just mixing with others from other geographical locations. Several participants noted that engaging with other cultures was best actioned in learning about others' experiences and backgrounds, rather than assuming there was a 'lack of diversity' in a classroom where all the students were from the same country or part of the world. There was recognition of the value of students and tutors having "very different interpretations of what it meant for them to be where they are' (A1 SRI). This tutor made a series of comments related to an activity observed in his class fitting this concept in the stimulated recall interview, noting that students could learn about different kinds of discrimination, as well as different understandings of inequality and equal opportunity, as forms of intercultural competence development. Students in this tutor's class reflected positively on the activity in their focus group, which seemed to be easy for them to do as the group of students was visibly diverse, coming from more than ten different countries on four different continents - a feature of the cohort several students commented on as a truly positive aspect of their programme. The students expressed 'happiness' about engaging with other cultures, and one even commented that 'a non-diverse environment would actually be wrong' (A1 FG). Another student indicated that engaging with other cultures was the most important factor, more important than even following what others talked about in class, but clarifying that exposure to new ideas, even if not understood, adds to the overall learning experience. This positivity was also found in another focus group, with one student stating, 'It was really good because different people that mean different point of view that mean different perspectives. Yeah, it's a cliché but it's true' (B2 FG).

\section{Construction of a comfortable third space}

With or without reservations, the participants in this study were generally focused on the idea that intercultural competence development can only happen in a supportive, comfortable environment, where diversity is valued, and different perspectives can be shared openly. 
These ideas lend well to the concept of a metaphorical third space, something jointly constructed by members of a community. The third space in this study was that safe space that the participants consciously attempted to construct for learning and development to take place. The construction of this third space was realised in examples from the interview data.

Some general concepts related to a comfortable space had to do with a certain freedom from evaluation or judgement needed for students to participate openly. One tutor wanted students 'to feel comfortable and not necessarily judged for making some comments that you might you know be a little hesitant to make' (A1 PI). He also considered how to 'create an environment where students feel respected, like their preferences are legitimate, that type of thing' (A1 PI). But there was uncertainty as to how to actively create such a space for students.

The conscious construction of the third space / sphere of interculturality was noted by most tutors. For example, one commented on the curriculum: 'we have one unit called [xx] where students have to work in teams, and we're deliberately sort of trying to get a big nice mix of students within it, so this is where they learn from each other across the group, and you know, it's interesting' (D1 PI). Conscious third space construction was especially noted by the tutors who reflected on both physical and metaphorical spaces, for one, taking into consideration students' lack of consciousness of his efforts:

I presented it in a way that this is your seminar this is your space so you shouldn't be shy to make the best use of this space, so my guess is they wouldn't be conscious of the fact that I'm doing this to address cultural aspects... (A2 PI)

The conscious construction of a comfortable space was further identified by the tutors' willingness to support students, by encouraging them to ask questions-one tutor telling students to interrupt with questions if they are so inclined, and the other tutor giving time to students at the end of class to ask individual questions since they are less inclined to ask during the lecture.

Such inclination raises the issues of students' classroom anxiety and shyness. While both tutors from the same faculty commented that they tell their students 'don't be shy', they both admitted this approach did not work, at least not directly. One tutor mentioned that such encouragement would lead to laughter, which would lead to students feeling more comfortable about opening up in the classroom. But he admitted this was only a minor improvement to a major dilemma.

In one especially diverse class, the tutor commented in the stimulated recall interview that stereotypes about participation were apparent, and so he had to actively work to create a balance in the classroom:

[What] was challenging for me was the participation at that point tended to mainly be white males, and it was pretty hard to get women and people of colour, you might say, into the conversation, I had to suppress them to let others speak so we had more equality... (A1 SRI)

This reflects a particular Western view on balance and equality where participation is recognised in the form of all students speaking up in class. We recognise that some students would feel uncomfortable when encouraged to speak, which is failing to form a shere of interculturality (e.g. Western cultures usurp others). These students can contribute in other ways, and the construction of the comfortable third space forms where different ways of participating are encouraged. 
It was noted in all focus groups that none of the efforts to create a comfortable space were formally constructed into the programmes. In one of the focus groups, one student commented, 'it [intercultural competence development] could be built into the programme itself and really see us as experts, it would bring a lot more to the programme and add richness' (A1 FG). This was a notable suggestion, given that the student's tutor had hinted at the idea that the onus for the construction of a comfortable space was with the students: 'I think for the most part they generally kind of they get it more from their peers than from me' (A1 PI).

\section{Discussion and Conclusion}

The findings of this study have highlighted the importance of establishing a sphere of interculturality for the construction of a comfortable third space that is sufficiently supportive, safe, and comfortable for the negotiation of identities and the development of intercultural competence to take place. As noted earlier, being an active member of a diverse community is key, as it influences participants' sense of self in their interactions with others. The development of a sense of self in this context needs to be managed as the participants attempt to negotiate a comfortable third space with each other. This navigation will inevitably be interpreted differently, depending on people's backgrounds.

Before moving to the implications of our findings, it is important to note the limitations of the study. In a study such as this in which we are raising issues of intercultural competence with participants, we must acknowledge that there is a certain inevitability that we may have influenced responses, as the participants may not place as much importance on these issues unprompted. Whereas the SRIs with tutors provided data from the observations to help alleviate problems with self-reporting, the focus groups relied on self-reported data that may have been influenced by selective memory or exaggeration - particularly in cases where students influenced each other's reports. Another consideration is the sample. As noted earlier, one tutor participant withdrew from the study following the preliminary interview, so data from that one faculty are limited. Furthermore, as the participants were volunteers, it is likely they were already interested in the topic and had something to say. That five tutors were originally from outside the UK (although all were residing permanently in the UK at the time the study was conducted), and all of the twenty-four student participants indicated through their contributions that they were from outside the UK, is evidence of the international profile of the postgraduate programmes at the university. But it could also suggest those with less international experience may not have been interested in the project. One final consideration is that the researchers also identify as international, so there may have been a certain element of participants leaving out explanations that may have been assumed to have been understood.

Despite these potential limitations, the implications of the study regarding policy and practice are considerable. While recommendations for supporting intercultural competence typically follow generic openness-to-engaging-with-other-cultures statements and activities, we focus on how three recommendations in particular from our study align with those of other scholars in recent work in an effort to create a stronger sense of urgency for these points. Our recommendations for supporting the development of a comfortable third space come out of the evidence presented for the themes, namely:

(a) the university could provide opportunities for community building that foster interdisciplinary collaboration (exploring ideas presented by Turner, Benessaiah, Warren, \& Iwaniec, 2015); 
(b) that while awareness raising is a good idea, there could be opportunities to move those activities further forward, making them more concrete through institutional engagement (supported by Smith, 2015); and

(c) postgraduate curricula could be revised to acknowledge the changing work environment of students' future lives, targeting transferable skills (along the lines of Johnson \& Parmenter, 2017).

Opportunities for community building were noted in tutor comments regarding interdisciplinary cooperation and collaboration (e.g. the Engineering tutor whose students applied Social Sciences conceptualisations of intercultural competence). Turner et al.'s (2017) study of the hierarchical tensions in collaborative interdisciplinary research: epistemic, structural, and affective, draw on some valuable points that could contribute to tutors' professional development. Their conclusion that such tensions are interdependent and provide valuable opportunities for self-reflective management could be made of this study as well, in that tutors should embrace, rather than avoid the tensions they experience, to help inform their practices and contribute to establishing a comfortable third space. Further opportunities for community building could be seen in consideration of the sense of community developed through particular actions. Being an active member of a diverse community is key, so a university programme that fosters intercultural interaction through its activities could be considered supportive of intercultural competence development. Of course, those activities would need to be objective-driven, and the objectives would need to be shared by students and academic staff alike. In our findings, there were examples of less overt community building, such as the tutor's use of the inclusive pronoun we in the classroom. There were also examples of community building occurring in non-academic settings (the pub, dinners, time with family and friends) that are too often ignored in university programme rhetoric. It may be a simple matter of university programmes acknowledging these other activities as opportunities. Rather than focusing solely on university-led community building prospects, they can incorporate opportunities outside the university as an unofficial, but significant, part of the programme.

Our findings also revealed significant student challenges in developing intercultural competence through awareness raising activities alone. The activities require institutional engagement beyond generic activities, 'building capacity by interrupting the usual', and making diversity visible (Smith, 2015). Raising awareness of intercultural competence is, in theory, a good idea, but students in our study voiced concern about the idea that simply addressing that cultural differences exist in a university programme may not equate to actual development. University programmes could embrace cultural difference by highlighting and emphasizing it where it may otherwise go unnoticed, and exploit awareness-raising activities as opportunities for development that could be built into the programme. The activities need to embrace diversity, and need to be a part of the university's overt efforts to develop intercultural competence, potentially in the form of extracurricular objectives and requirements.

In programme curricula, the development of intercultural competence was consistently identified as absent in our study. This problem was noted by Johnson and Parmenter (2017) in their study of $\mathrm{PhD}$ graduates in New Zealand, who argue that as career destinations change, the development of transferable skills has become a significant consideration in postgraduate curricula. As the work environment of postgraduates' future lives continually changes, often dramatically, curricula could be revised to take the work environment into account. While there was evidence in the study that tutors and students regularly related their intercultural competence development to the students' professional needs after graduation, there was little evidence that programmes were designed with this 
idea in mind. The recommendation here is for university programmes to revise curricula to provide structure for these thoughts, to convert them to actions, classroom activities, or assessments, and better prepare students for their future lives.

Evidence of good practice as agreed by participants and suggested general strategies and resources were collected and made publicly available on the project website. These strategies offer guidance toward the establishment of a space that is comfortable, and conducive to negotiation of multiple meanings and multiple identities. The strategies embrace the value of struggle in the negotiation, supporting the idea that the very nature of academic work requires constant evaluation and critical self-reflection.

We accept the principle of creating a supportive classroom environment in which staff and students can feel free to make their representations, negotiate meanings and move forward their state of knowledge. We recognise the pitfalls of assuming a 'comfortable' space is one in which people can feel relaxed, as that does not sit well with the dynamic nature of intercultural interactions. However, the ability to negotiate the conflict of values and interests, which is a necessary catalyst to creativity and development, occurs more effectively where there is a safe space in which participants can feel free to negotiate and address the conflict (Whitechurch, 2008). Furthermore, the processes of representation, identity construction and negotiation of meaning are always going to be open-ended. As academic cultures continue to develop and interact, so too must our efforts to make sense of them.

\section{References}

Appadurai, A. (2013). The Future as Cultural Fact: Essays on the Global Condition. Brooklyn, NY: Verso Books.

Bhabha, H. (1994). The Location of Culture. New York: Routledge.

Byram, M. (2014). Conceptualizing intercultural (communicative) competence and intercultural citizenship. In J. Jackson (Ed.), The Routledge handbook of language and intercultural communication (pp. 85-97). London: Routledge.

Deardoff, D.K. (2006) Identification and assessment of intercultural competence as a student outcome of internationalization, Journal of Studies in International Education, 10, 241266.

Dobinson, T. (2014). Occupying the 'Third Space': Perspectives and Experiences of Asian English Language Teachers. In K. Dunworth \& G. Zhang (Eds.), Critical Perspectives on Language Education: Australia and the Asia Pacific. London: Springer

Galloway, N. \& Rose, H. (2015). Introducing Global Englishes. Abingdon: Routledge.

Goldberg, A. E., \& Allen, K. R. (2015). Communicating qualitative research: Some practical guideposts for scholars. Journal of Marriage and Family, 77(1), 3-22.

Gutierrez, K. D. (2008). Developing a sociocultural literacy in the third space, Reading Research Quarterly, 43(2), 148-164.

Holliday, A. (2011). Intercultural Communication and Ideology, London: Sage.

Holliday, A. (2014). Culture, communication, context and power. In J. Jackson (Ed.), The Routledge Handbook of Language and Intercultural Communication (pp. 37-51). London: Routledge.

Ikas, K. \& Wagner, G. (Eds.) (2009). Communicating in the Third Space. London: Routledge.

Johnson, E. M., \& Parmenter, L. (2017). Transferable skills for global employability in PhD curriculum transformation. In Curriculum Transformation HERDSA Higher Education Research and Development Society of Australasia. Retrieved from 
https://researchcommons.waikato.ac.nz/handle/10289/11745

Jones, E. \& Brown, S. (Eds.) (2007). Internationalising Higher Education: Enhancing learning, teaching and curriculum. London:Routledge.

Kramsch, C. (1993). Context and culture in language teaching. Oxford University Press.

Kramsch, C. (2011) Theorizing translingual/transcultural competence. In G. Levine \& A. Phipps (Eds.), Critical and intercultural theory and language pedagogy (pp.15-31). Boston: Heinle.

Kramsch, C., \& Uryu, M. (2014). Intercultural contact, hybridity, and third space. In J. Jackson (Ed.), The Routledge handbook of language and intercultural communication (pp. 211-225). London: Routledge.

Kumaravadivelu, B. (2008). Cultural globalization and language education. Yale University Press.

LoBianco, J., Liddicoat, A. J. \& Crozet, C. (Eds.) (1999). Striving for the Third Place: Intercultural competence through language education. Melbourne: Language Australia

Pennycook, A. (2007). Global Englishes and Transcultural Flows, London: Routledge.

Piller, I. (2012). Intercultural Communication: An Overview. In C. Paulston, S. Kiesling, and E. Rangel (Eds.), The Handbook of Intercultural Discourse and Communication (pp.3-18). Oxford: Blackwell.

Smith, D. G. (2015). Diversity's promise for higher education: Making it work ( $2^{\text {nd }}$ ed.). Baltimore: Johns Hopkins University Press.

Soja, E. W. (1996). Thirdspace: Journeys to Los Angeles and other real-and-imagined places. Oxford: Basil Blackwell.

Turner, V. K., Benessaiah, K., Warren, S., \& Iwaniec, D. (2015). Essential tensions in interdisciplinary scholarship: navigating challenges in affect, epistemologies, and structure in environment-society research centers. Higher Education, 70(4), 649-665.

Vertovec, S. (2007). Super-diversity and its implications, Ethnic and Racial Studies, 30(6), 1024-1054.

Vertovec, S. (2009). Transnationalism. London: Routledge.

Whitchurch, C. (2008). Shifting identities and blurring boundaries: The emergence of third space professionals in UK higher education. Higher Education Quarterly, 62(4), 377-396.

Yin, R. (2014). Case Study Research: Design and Methods (5 ${ }^{\text {th }}$ ed.). Los Angeles: Sage, 